J. Lake Sci.(湖泊科学) , 2016, 28(5): 994-1003

DOI 10. 18307/2016. 0508

(c) 2016 by Journal of Lake Sciences

\title{
梁子湖水质时空格局分析
}

\author{
秦 云 $^{1,2}$, 李艳蓄 ${ }^{1,2}$, 吴丽秀 ${ }^{3}$, 陈红兵 ${ }^{1,2}$, 李兆华 ${ }^{1,2 * *}$, 黄运新 ${ }^{1,2 * *}$ \\ ( 1 : 湖北大学资源环境学院,武汉 430062) \\ (2: 区域开发与环境响应湖北省重点实验室,武汉 430062) \\ (3: 湖北大学数学与统计学院, 武汉 430062)
}

摘 要: 基于大样本监测数据, 从点位、湖区、全局 3 个层次,对梁子湖水质的季节变化和空间差异进行综合分析,发现梁 子湖水质存在显著的季节差异和较大的空间差异: (1) 季节上,夏、秋、冬季污染相对较重, 春季污染相对较轻; 夏、秋季主 要污染指标为高锰酸盐指数 $\left(\mathrm{COD}_{\mathrm{Mn}}\right)$, 冬季为总氮 $(\mathrm{TN}) ;(2)$ 空间上, 东梁子湖和牛山湖污染相对较重, 西梁子湖污染相 对较轻; 东梁子湖主要污染指标为 $\mathrm{COD}_{\mathrm{Mn}}$ 、总磷 (TP) 和 $\mathrm{TN}$, 牛山湖为 $\mathrm{COD}_{\mathrm{Mn}}$ 、 $\mathrm{TN}$ 和氨氮, 西梁子湖为 $\mathrm{COD}_{\mathrm{Mn}}$ 和 TN. 研究 结果有助于更好地了解梁子湖水质的时空变化特点,进而制定有针对性的保护措施和管理对策.

关键词: 梁子湖;水质;季节变化;空间差异

\section{Analysis on the spatial-temporal patterns of water quality in Lake Liangzi}

\author{
QIN Yun ${ }^{1,2}$, LI Yanqiang ${ }^{1,2}$, WU Lixiu $^{3}$, CHEN Hongbing ${ }^{1,2}$, LI Zhaohua ${ }^{1,2 * *}$ \& HUANG Yunxin ${ }^{1,2 * *}$ \\ (1: School of Resource and Environment, Hubei University, Wuhan 430062, P.R. China) \\ (2: Hubei Provincial Key Laboratory of Regional Development and Environmental Response, Wuhan 430062, P.R.China) \\ (3: School of Mathematics and Statistics, Hubei University, Wuhan 430062 , P.R.China)
}

\begin{abstract}
Based on large sets of monitoring data, this paper analyzed the seasonal variation and spatial difference in four main parameters of water quality at Lake Liangzi, examining the water quality in three different spatial levels in individual sampling locations, subdivided lake areas and the entire lake. The major pollution parameters of $\mathrm{COD}_{\mathrm{Mn}}$, total nitrogen(TN) and total phosphorus ( TP) were examined at the East Lake Liangzi, $\mathrm{COD}_{\mathrm{Mn}}$, TN and ammonia nitrogen at the Lake Niushan, $\mathrm{COD}_{\mathrm{Mn}}$ and $\mathrm{TN}$ at the West Lake Liangzi. Results showed that there were significantly spatial and seasonal changes. Pollution was relatively serious in summer and fall as $\mathrm{COD}_{\mathrm{Mn}}$ was high and in winter as TN was high, while the pollution was relatively light in spring. The results are helpful to better understand the spatial and seasonal patterns of water quality in Lake Liangzi and to find practical strategies for water quality protection and management.
\end{abstract}

Keywords: Lake Liangzi; water quality; seasonal variation; spatial difference

湖泊蓄积了地表上绝大部分可利用的淡水资源, 是人类赖以生存的主要水源地. 湖泊也是湿地生态系 统的重要组成部分, 为各种生物提供宝贵的栖息地, 有助于促进生物多样性. 湖泊还是水产养殖、观光旅游 的理想地点, 具有重要的经济价值. 简言之, 湖泊对人类的生存以及社会经济的发展均具有重要意义. 然而, 随着经济的发展和资源的过度开发加上疏于保护,包括中国在内的一些发展中国家的湖泊水环境正在恶 化, 严重威胁水资源生态安全 ${ }^{[1]}$. 我国是世界上湖泊较多的国家之一, 湖泊总面积超过 $9 \times 10^{4} \mathrm{~km}^{2[2]}$. 我国同 时也是世界上湖泊污染比较严重的国家之一. 2014 年我国重点湖泊 (水库) 受到污染的比例高达 $38.7 \%$, 其 中重度污染的占 $8.1 \%$, 主要污染指标为总磷 $(\mathrm{TP})$ 、化学需氧量和高锰酸盐指数 $\left(\mathrm{COD}_{\mathrm{Mn}}\right)$, 重点湖泊 (水库) 中富营养化的比例也高达 $24.2 \%{ }^{[3]}$. 从这些数据可以看出, 我国湖泊污染问题十分突出, 湖泊的保护与管理

*2015-07-23 收稿;2015-12-01 收修改稿. 秦云 (1990 ), 女, 硕士研究生;E-mail: shuyunchenyun@ 163.com. 并 列第一作者:李艳蓄 $(1977 \sim)$,女,博士;E-mail:dark@ hubu.edu.cn.

** 通信作者;E-mail:zli@ hubu.edu.cn,E-mail:y.huang@hubu.edu.cn. 
面临艰巨的挑战.

为了有效地保护地表水资源, 我国制订了《地表水环境质量标准 $\rangle^{[4]}$ 和《水和废水监测分析方法》 ${ }^{[5]}$, 为 包括湖泊在内的地表水环境监测提供了依据. 根据相关依据, 我国每年对主要河流、湖泊、水库的环境状况 进行例行监测并发布年度报告. 毫无疑问, 这种例行监测对宏观了解地表水的水质现状, 实行必要的分类管 理非常有益. 不过, 例行监测一般具有采样点少, 针对性不强的缺点, 对研究解决某些实际问题往往帮助 不大.

地表水环境研究需要解决的实际问题之一是了解水质时空分布格局, 分析污染成分和源头. 相关研究 从对象来看大体分为两类,一类是针对空间跨度较大、流动性较强的河流 ${ }^{[6-8]}$, 另一类是针对空间跨度较小、 流动性较弱的湖泊或水库 ${ }^{[9-12]}$. 从水环境指标来看, 既有针对部分指标的重点分析 ${ }^{[7,12-13]}$, 也有针对多种指

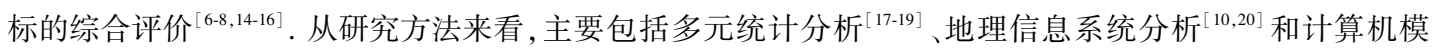
拟 ${ }^{[21]}$ 等.

为此, 本文以梁子湖为例, 通过大样本监测和多层次比较分析方法, 分析梁子湖整体的水质状况、空间 差异和空间分布模式, 以及各个湖区的达标情况, 研究梁子湖的水质时空格局. 与以前的研究相比 ${ }^{[22-25]}$, 每 个季节布设的点位数有显著的增加, 因此能够更为有效地分析水质的空间差异和季节变化, 了解水质污染 特点, 为梁子湖的水环境保护提供依据.

\section{1 研究区域概况}

梁子湖 $\left(30.08^{\circ} \sim 30.38^{\circ} \mathrm{N}, 114.37^{\circ} \sim 114.66^{\circ} \mathrm{E}\right.$ ) 位于长江中游南岸, 是湖北省第二大淡水湖, 在常年平均 水位时, 面积 $225 \mathrm{~km}^{2}$, 平均水深 $2.54 \mathrm{~m}$, 正水量 $6.5 \times 10^{8} \mathrm{~m}^{3}$, 容水量居全省湖泊之首. 梁子湖人湖河港多达 30 余条, 其中主要人湖河港为高桥河. 这些河港顺着地势经地表径流汇人梁子湖. 梁子湖出湖口仅磨刀矶一 处, 湖水排人长江 (图 1). 整个梁子湖按地理位置和历史沿革可划分为东梁子湖、牛山湖和西梁子湖 3 个湖 $区^{[25]}$. 其中, 牛山湖和东梁子湖被牛山大坝分隔, 而东梁子湖和西梁子湖交汇于梁子岛及其西侧的岛屿群. 牛山湖和西梁子湖为地表水环境功能 II 类区, 是珍贵鱼类保护区、鱼虾产卵场, 而东梁子湖为地表水环境功 能而类区, 是一般鱼类保护区 ${ }^{[26]}$.

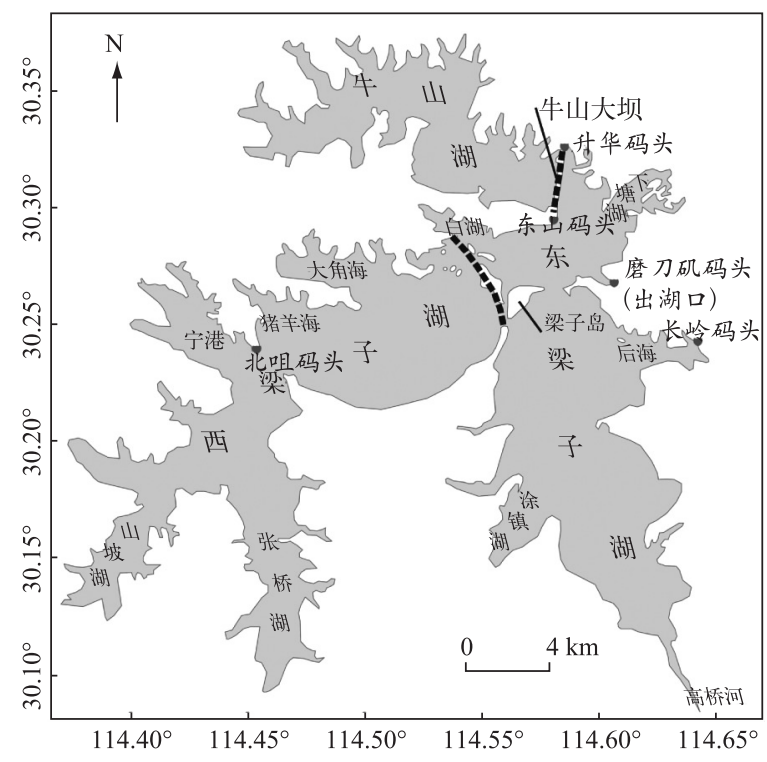

图 1 梁子湖示意图

Fig.1 Study area of Lake Liangzi 


\section{2 材料与方法}

\section{1 数据采集}

结合梁子湖地形特点以及人湖河流的分布,于 2012 年的夏季 ( 7 月)、秋季 (10 月)、冬季( 12 月) 和 2013 年的春季 ( 3 月) 对梁子湖水体进行调查采样. 采样时利用 GPS 定位, 根据现场测得的水深确定采样深度, 4 个季节共采集 300 个水样, 其中春季 44 个 (西梁子湖 15 个、牛山湖 14 个、东梁子湖 15 个), 夏季 149 个(西 梁子湖 67 个、牛山湖 31 个、东梁子湖 51 个), 秋季 64 个 (西梁子湖 31 个、牛山湖 14 个、东梁子湖 19 个), 冬 季 43 个 (西梁子湖 16 个、牛山湖 8 个、东梁子湖 19 个), 每个季节采样活动历时 $2 \sim 3$ 天. 具体采样方法参照 《水质采样技术指导》进行 ${ }^{[27]}$.

主要测定的水质指标包括水深、水温、 $\mathrm{pH}$ 值、透明度、溶解氧、 $\mathrm{COD}_{\mathrm{Mn}} 、 \mathrm{TP}$ 、总氮 $(\mathrm{TN})$ 、氨氮 $\left(\mathrm{NH}_{3}-\mathrm{N}\right)$ 等. 其中前 5 个指标现场测定: 水深在没有水草的地方利用 EcoSounder 回声仪测定, 有水草的地方通过钢尺测 定; 水温、 $\mathrm{pH}$ 值、溶解氧等利用美国哈希水质仪 (DS5 系列) 测定; 透明度通过塞氏盘测定. 而后 4 个指标在 各采样点采集 $600 \mathrm{ml}$ 水样, 利用浓硫酸固定后带回实验室测定: $\mathrm{COD}_{\mathrm{Mn}}$ 浓度采用酸性高锰酸钾氧化法测 定 ${ }^{[28]}$; TP 浓度采用钿酸铵分光光度法测 ${ }^{\text {定 }}{ }^{[29]}$; TN 浓度采用碱性过硫酸钾消解紫外分光光度法测 ${ }^{\left[{ }^{2}\right.}{ }^{[30]}$; $\mathrm{NH}_{3}-\mathrm{N}$ 浓度采用纳氏试剂分光光度法测定 ${ }^{[31]}$.

限于篇幅, 本文仅针对后 4 个关键指标, 即 $\mathrm{COD}_{\mathrm{Mn}}$ 、 $\mathrm{TP} 、 \mathrm{TN}$ 和 $\mathrm{NH}_{3}-\mathrm{N}$, 从点位、湖区、全局 3 个层次对梁子 湖的水质时空格局进行分析和比较.

\section{2 数据分析}

2.2.1 水质类别空间分布图 基于《地表水环境质量标准》 ${ }^{[4]}$ 对采样点的水质进行类别划分, 在水域功能区 标准限值内的, 将各类标准限值作为分类的界限, 共划分为 5 类; 超出水域功能区标准限值的, 统归为 1 类 (劣 $\mathrm{V}$ 类). 对不同的水质类别采用不同的颜色标记, 结合采样点的地理坐标信息, 绘制水质类别空间分布 图. 通过水质类别空间分布图, 分析点位层次的水质状况、达标情况和水质空间差异. 其中, 水质状况根据各 类水质占的百分比来评价; 达标情况根据超标比例来评价; 水质空间差异根据包含的水质类别数量来评价.

2.2.2 箱线图 是一种用来显示数据分散情况的统计图, 由 “箱” 和 “线” 组成,包括一个箱体和两条分别从箱 体顶端向上和底端向下的垂直延长线 (触须). 箱体下边界代表第一四分位数 $\left(Q_{\mathrm{L}}\right)$, 上边界代表第三四分位 数 $\left(Q_{\mathrm{U}}\right)$, 箱体内部的线段 (中位线) 代表中位数, 箱体长度代表四分位距 $(I Q R)$; 从箱体边界向下延伸的触须 终点位置为不小于 $Q_{\mathrm{L}}-1.5 I Q R$ 的最小观测值, 从箱体边界向上延伸的触须终点位置为不大于 $Q_{\mathrm{U}}+1.5 I Q R$ 的最大观测值. 触须终点的线段为临界点, 临界点之外为异常值. 通过指标浓度箱线图, 分析湖区层次的水 质状况和达标情况. 其中, 水质状况是对每个湖区各个指标浓度的季节变化模式进行综合, 根据共同的变化 模式来评价; 达标情况根据箱体与达标线的相对位置来评价.

2.2.3 方差分析 是一种能分解数据变异来源的统计方法, 用来识别数组间差异的显著性水平等. 根据考虑 的因素个数可分为单因素、双因素和多因素方差分析. 单因素方差分析数组间是否存在显著性差异用 $F$ 检 验; 需进一步区分具体两个数组的差异用多重比较检验, 检验方法用最小显著差异法 (LSD), 检验结果用柱 形图和字母标记法识别. 通过方差分析湖区层次的水质空间差异和全局层次的水质状况. 其中, 水质空间差 异是对湖区进行单因素方差分析, 根据 $F$ 检验的显著性水平来评价; 水质状况是对季节进行单因素方差分 析, 根据多重比较检验的结果来评价.

2.2.4 Global Moran's I 是一个反映空间自相关的统计量 ${ }^{[32]}$, 用来评估空间分布模式是聚集、离散还是随机 模式, 显著性水平采用 $Z$ 检验. Global Moran's I 的取值在 $-1 \sim 1$ 之间, 其中, 正值且检验结果显著代表聚集 模式 (cluster pattern), 即指标浓度较高的样点周围指标浓度也较高, 或者指标浓度较低的样点周围指标浓度 也较低; 负值且检验结果显著代表离散模式 (dispersion pattern), 即指标浓度较高的样点周围指标浓度较低, 或者指标浓度较低的样点周围指标浓度较高; 其他情况代表随机模式 (random pattern), 即指标浓度的空间 分布没有规律.

2.2.5 Anselin Local Moran's I 是一个用来识别具有统计显著性的热点、冷点和空间异常值的统计量 ${ }^{[33]}$, 显 著性水平采用 $Z$ 检验. 可将样点分成 5 类: $\mathrm{HH}$ (热点, 指标浓度较高的样点周围指标浓度也较高)、 $\mathrm{LL}$ (冷点, 
指标浓度较低的样点周围指标浓度也较低)、HL( 异常值, 指标浓度较高的样点周围指标浓度较低)、LH( 异 常值, 指标浓度较低的样点周围指标浓度较高) 和检验结果不显著. 由热点组成的空间分布图称为高值聚集 空间分布图, 由冷点组成的称为低值聚集空间分布图. 通过 Global Moran's I 和 Anselin Local Moran's I 分析全 局层次的水质空间分布模式. 先根据 Global Moran's I 判断每个季节各个指标浓度的空间分布是否呈聚集模 式,对呈聚集模式的情况再根据 Anselin Local Moran's I 分析识别高值聚集区和低值聚集区.

此外, 全局层次的水质空间差异根据变异系数 $(C v)$ 来评价. 水质类别空间分布图、箱线图和变异系数通 过 Matlab R2010b 软件完成, 方差分析通过 SPSS 19.0 软件完成, Global Moran's I 和 Anselin Local Moran's I 分 析通过 ArcGIS 10.1 软件完成 ${ }^{[34]}$.

\section{3 研究结果}

\section{1 点位层次的水质时空格局分析}

3.1.1 水质状况 梁子湖整体 $\mathrm{COD}_{\mathrm{Mn}}$ 浓度在春季相对较低, 以 II 类水质为主 (占 $84 \%$ ); 夏季相对较高, 包含 II 、III 、IV、V 各类水质,其中 IV 类占 $67 \%$; 秋季也相对较高,包含 III IV、V 各类水质,其中 IV 类占 $70 \%$; 冬季 相对较低, 包含 I 、II、III IV 各类水质, 其中 II 类占 $63 \%$ (图 2a). TP 浓度在春季相对较低, 以 II 类水质为主 (占 $80 \%$ ) ; 夏季有所上升, 包含 I 、II、II 、IV、V 各类水质, 其中 II 、III类分别占 $36 \% 、 37 \%$; 秋季有所下降, 包 含 I 、II 、II 、IV 各类水质, 其中 II 、III类分别占 $52 \% 、 22 \%$; 冬季相对较低, 包含 I 、II 、III各类水质, 其中 II 类 占 $74 \%$ (图 2b). TN 浓度在春季处于中等水平, 包含 II 、III IV、V 各类水质, 其中 III类占 $64 \%$; 夏季也处于中 等水平,包含 II 、III、IV、V、劣 V 各类水质, 其中 III类占 $67 \%$, 但局部 (靠近牛山大坝的牛山湖区域) 存在明显 的水质恶化现象, 水质为劣 V 类 (占 5\%); 秋季有所下降,包含 II 、III类水质,其中 II 类占 $59 \%$; 冬季相对较 高, 包含 I 、II、III、IV、V、劣 V 各类水质, 其中 III、IV 类分别占 $35 \% 、 47 \%$ (图 2c c). $\mathrm{NH}_{3}-\mathrm{N}$ 浓度在春、夏、秋季 相对较低,均以 II 类水质为主(春、夏、秋季分别占 $98 \% 、 83 \% 、 89 \%$ ) ; 冬季处于中等水平,包含 II 、II 、 IV 各类 水质,其中III类占 $70 \%$ (图 2d).

3.1.2 达标情况 东梁子湖夏、秋季的 $\mathrm{COD}_{\mathrm{Mn}}$ 以及冬季的 $\mathrm{TN}$ 超标较严重 (超标比例分别为 $75 \% 、 63 \%$ 和 $68 \%$ ); 牛山湖春季的 TN 超标较严重 (超标比例 79\%), 夏季的 $\mathrm{COD}_{\mathrm{Mn}}$ 和 TN 超标非常严重 (超标比例分别为 $97 \%$ 和 $87 \%$ ), 秋季的 $\mathrm{COD}_{\mathrm{Mn}}$ 以及冬季的 $\mathrm{COD}_{\mathrm{Mn}}$ 、TN 和 $\mathrm{NH}_{3}-\mathrm{N}$ 超标非常严重 (超标比例均为 $100 \%$ ); 西梁子 湖春季的 $\mathrm{TN}$ 超标较严重 (超标比例 $67 \%$ ), 夏季的 $\mathrm{COD}_{\mathrm{Mn}}$ 和 $\mathrm{TN}$ 、秋季的 $\mathrm{COD}_{\mathrm{Mn}}$ 以及冬季的 $\mathrm{TN}$ 超标非常严重 （超标比例分别为 $93 \% 、 85 \% 、 100 \%$ 和 $88 \%$ ).

3.1.3 水质空间差异 梁子湖春季 TP 和 TN 浓度空间差异较大 (均包含 4 个类别水质) ; 夏季 $\mathrm{COD}_{\mathrm{Mn}}$ 、 $\mathrm{TP}$ 和 $\mathrm{TN}$ 浓度空间差异较大 (分别包含 4、5 和 5 个类别水质); 秋季 TP 浓度空间差异较大 (包含 4 个类别水质); 冬季 $\mathrm{COD}_{\mathrm{Mn}}$ 和 $\mathrm{TN}$ 浓度空间差异较大 (分别包含 4 和 6 个类别水质).

\section{2 湖区层次的水质时空格局分析}

3.2.1 水质状况 各指标浓度中位数的季节变化主要有两种模式: (1) 夏、秋季高, 春、冬季低; (2) 夏、冬季 高, 春、秋季低. 东梁子湖 $\mathrm{COD}_{\mathrm{Mn}}$ 和 $\mathrm{TP}$ 浓度的季节变化符合模式 (1), 而 $\mathrm{TN}$ 和 $\mathrm{NH}_{3}-\mathrm{N}$ 浓度符合模式 (2). 牛 山湖 $\mathrm{COD}_{\mathrm{Mn}}$ 浓度的季节变化符合模式 (1); 而 $\mathrm{TP}$ 浓度接近模式 (1), 但夏季偏低; TN 浓度接近模式 (2), 但 春季偏高; $\mathrm{NH}_{3}-\mathrm{N}$ 接近模式 (2), 但夏季偏低. 西梁子湖 $\mathrm{COD}_{\mathrm{Mn}}$ 浓度的季节变化符合模式 (1), 而 TP、TN 和 $\mathrm{NH}_{3}-\mathrm{N}$ 浓度符合模式 (2). 以 3 个湖区指标浓度中位数的季节变化模式为基础进行综合分析,结果表明,梁 子湖整体 $\mathrm{COD}_{\mathrm{Mn}}$ 浓度在夏、秋季相对较高, 春、冬季相对较低; TP 浓度在春季相对较低; $\mathrm{TN}$ 浓度在夏、冬季相 对较高, 秋季相对较低; $\mathrm{NH}_{3}-\mathrm{N}$ 浓度在冬季相对较高, 春、秋季相对较低.

3.2.2 达标情况 东梁子湖夏季的 $\mathrm{COD}_{\mathrm{Mn}}$ 超标非常严重 (箱体全部高于达标线), 秋季的 $\mathrm{COD}_{\mathrm{Mn}}$ 以及冬季的 $\mathrm{TN}$ 超标较严重 (箱体均有 3/5 高于达标线) (图 3a) ; 牛山湖春季的 $\mathrm{TN}$ 、夏季的 $\mathrm{COD}_{\mathrm{Mn}}$ 和 $\mathrm{TN}$ 、秋季的 $\mathrm{COD}_{\mathrm{Mn}}$ 、 TP 和 TN 以及冬季的 $\mathrm{COD}_{\mathrm{Mn}}$ 、TN 和 $\mathrm{NH}_{3}-\mathrm{N}$ 超标非常严重(箱体分别有 $1 、 1 、 1 、 1 、 4 / 5 、 4 / 5 、 1 、 1$ 和 1 高于达标 线) (图 3b) ; 西梁子湖春季的 $\mathrm{TN}$ 、夏季的 $\mathrm{COD}_{\mathrm{Mn}}$ 和 $\mathrm{TN}$ 、秋季的 $\mathrm{COD}_{\mathrm{Mn}}$ 以及冬季的 $\mathrm{TN}$ 超标非常严重 $($ 箱体分 别有 4/5、1、1、1 和 1 高于达标线), 秋季的 TN 超标较严重(箱体有 3/5 高于达标线) (图 3c).

3.2.3 水质空间差异 单因素方差分析结果表明, 梁子湖春季 $\mathrm{NH}_{3}-\mathrm{N}$ 浓度空间差异较大 $(P<0.05)$; 夏季 $\mathrm{TP}$ 、 


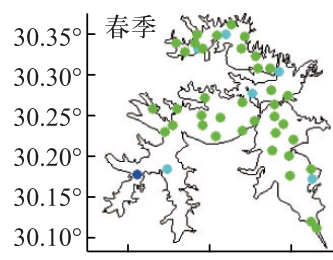

$114.4^{\circ} 114.5^{\circ} 114.6^{\circ}$

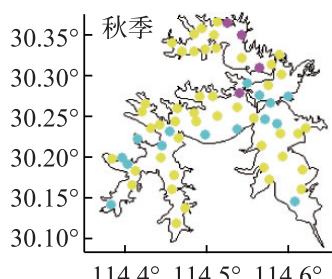

$114.4^{\circ} 114.5^{\circ} 114.6^{\circ}$

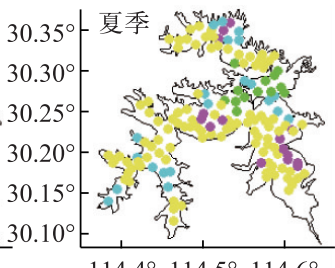

$114.4^{\circ} 114.5^{\circ} 114.6^{\circ}$

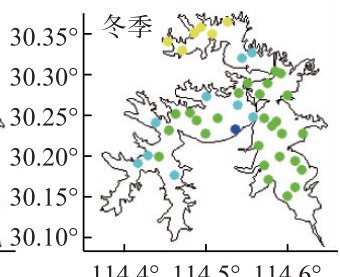

(a) $\mathrm{COD}_{\mathrm{Mn}}$
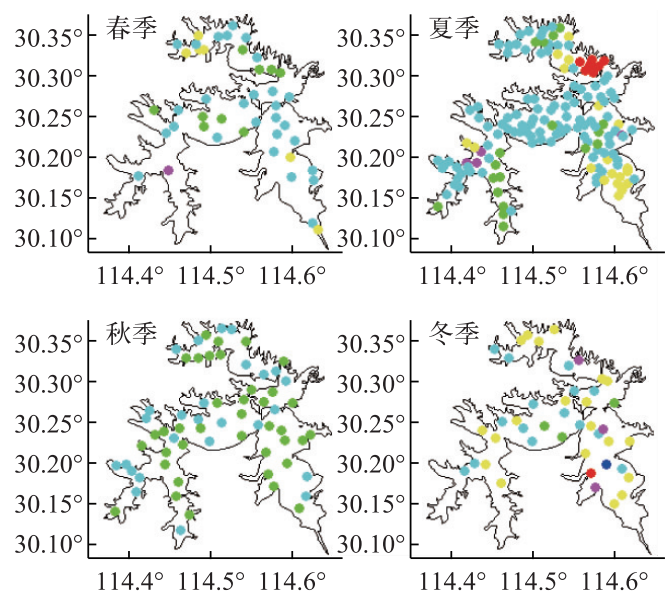

(c) $\mathrm{TN}$
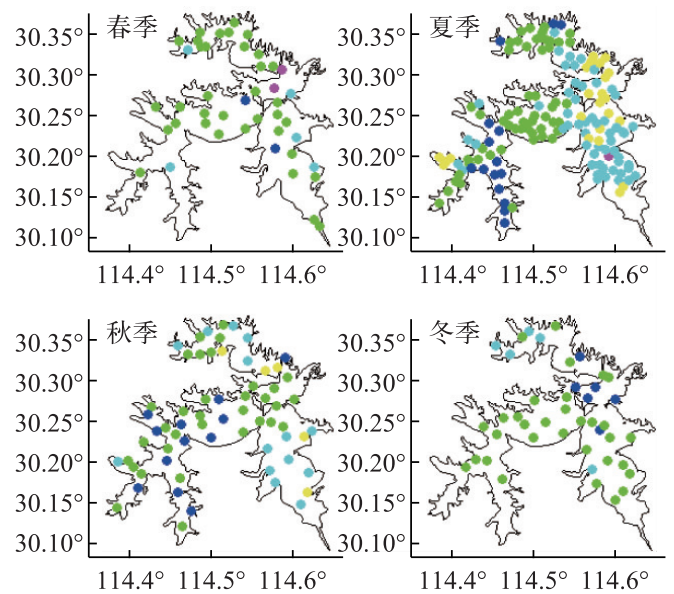

(b) $\mathrm{TP}$
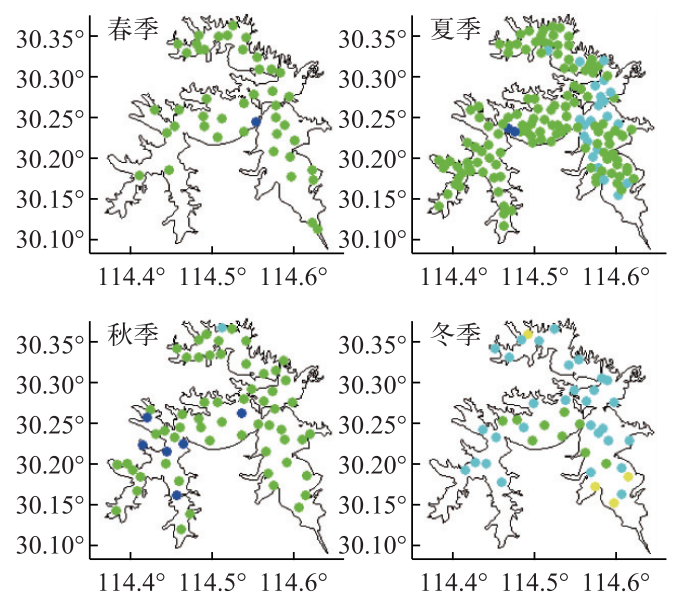

(d) $\mathrm{NH}_{3}-\mathrm{N}$

图 2 梁子湖各采样点主要指标水质类别的空间分布

(蓝色为 $\mathrm{I}$ 类, 绿色为 II 类,青色为 III 类, 黄色为 $\mathrm{IV}$ 类,粉色为 $\mathrm{V}$ 类,红色为劣 $\mathrm{V}$ 类)

Fig.2 Spatial distribution of water quality classification of main parameters in each sampling site of Lake Liangzi

$\mathrm{TN}$ 和 $\mathrm{NH}_{3}-\mathrm{N}$ 浓度空间差异非常大 $(P<0.01)$; 秋季 $\mathrm{COD}_{\mathrm{Mn}}$ 、TP 和 $\mathrm{NH}_{3}-\mathrm{N}$ 浓度空间差异非常大 $(P<0.01)$, TN 浓度空间差异较大 $(P<0.05)$; 冬季 $\mathrm{COD}_{\mathrm{Mn}}$ 和 $\mathrm{NH}_{3}-\mathrm{N}$ 浓度空间差异非常大 $(P<0.01)$, TP 浓度空间差异较大 $(P<0.05)$.

\section{3 全局层次的水质时空格局分析}

3.3.1 水质状况 单因素方差分析发现, 梁子湖整体 $\mathrm{COD}_{\mathrm{Mn}} 、 \mathrm{TP} 、 \mathrm{TN}$ 和 $\mathrm{NH}_{3}-\mathrm{N}$ 浓度的季节差异均非常显著 $(P<$ $0.01)$. 多重比较分析结果显示, 梁子湖整体 $\mathrm{COD}_{\mathrm{Mn}}$ 浓度在夏、秋季相对较高, 春、冬季相对较低; $\mathrm{TP}$ 浓度在夏 季相对较高, 春、秋、冬季相对较低; TN 浓度在冬季相对较高, 夏季次之, 春季再次之, 秋季相对较低; $\mathrm{NH}_{3}-\mathrm{N}$ 浓度在冬季相对较高,夏季次之,春、秋季相对较低(图 4).

3.3.2 达标情况 变异系数分析表明,春季梁子湖整体 TP 浓度空间差异非常大 $(C v=1.19)$, TN 浓度空间差 异较大 $(C v=0.40)$; 夏季 TP 浓度空间差异非常大 $(C v=0.67), \mathrm{COD}_{\mathrm{Mn}} 、 \mathrm{TN}$ 和 $\mathrm{NH}_{3}-\mathrm{N}$ 浓度空间差异较大 $(C v=$ $0.30 、 0.47 、 0.37)$; 秋季 TP 浓度空间差异非常大 $(C v=0.70), \mathrm{NH}_{3}-\mathrm{N}$ 浓度空间差异较大 $(C v=0.44)$; 冬季 $\mathrm{COD}_{\mathrm{Mn}} 、 \mathrm{TP} 、 \mathrm{TN}$ 和 $\mathrm{NH}_{3}-\mathrm{N}$ 浓度空间差异较大 $(C v=0.35 、 0.40 、 0.40 、 0.32)$. 

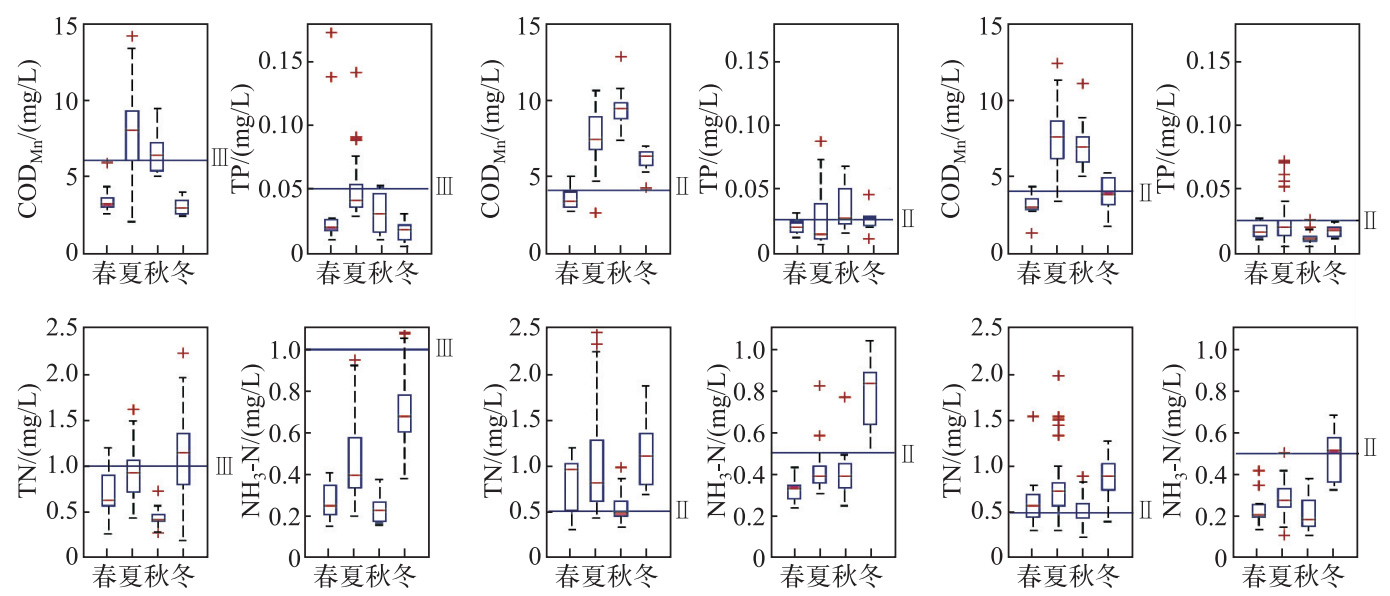

(a)东梁子湖

(b)牛山湖

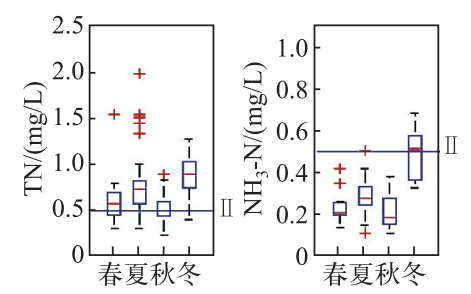

(c)西梁子湖

图 3 梁子湖各湖区主要指标浓度箱线图

(平行于横坐标的直线代表对应湖区的水质达标浓度限值, 称为达标线)

Fig. 3 Boxplots of concentration of main water quality parameters in each season at each subdivided lake of Lake Liangzi
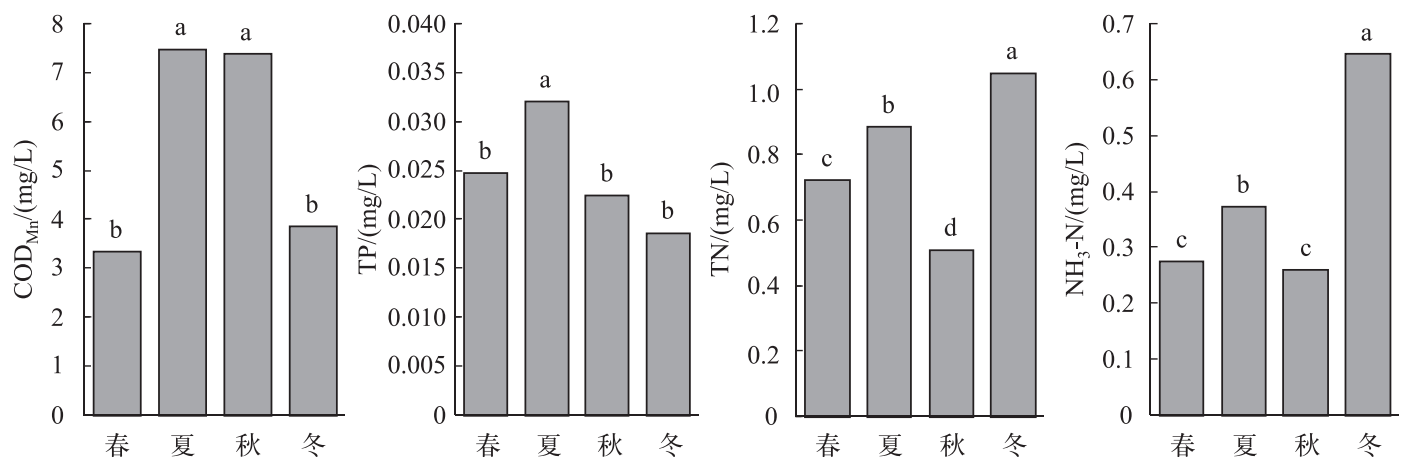

图 4 梁子湖主要指标浓度均值及季节差异

(同种指标柱形上方的字母不同表示两季节存在显著差异,相同表示无显著差异)

Fig.4 Average concentration of main water quality parameters in each season and the significant difference from season to season at Lake Liangzi

3.3.3 水质空间分布模式 Global Moran's I 分析发 现, 梁子湖春季的 $\mathrm{TP} 、 \mathrm{TN}$ 和 $\mathrm{NH}_{3}-\mathrm{N}$, 夏季的 $\mathrm{COD}_{\mathrm{Mn}}$ 、 $\mathrm{TP} 、 \mathrm{TN}$ 和 $\mathrm{NH}_{3}-\mathrm{N}$, 秋、冬季的 $\mathrm{COD}_{\mathrm{Mn}} 、 \mathrm{TP}$ 和 $\mathrm{NH}_{3}-\mathrm{N}$ 浓 度空间分布呈聚类模式 (表 1). 对 Global Moran’s I 分析结果呈聚集模式的季节指标, 分别进行 Anselin Local Moran's I 分析,绘制各个季节指标的高值/低值 聚集空间分布图 (共 13 张), 将其进行空间叠置得到 图 5 , 显示热点/冷点的总体空间分布情况, 热点/冷 点密度大的区域在全年中出现高值/低值的频率大, 污染较重/较低. Anselin Local Moran's I 分析显示, 高 值聚集区主要分布在东梁子湖和牛山湖的大部分区 域, 以及西梁子湖的局部区域(图 5a); 低值聚集区主
表 1 梁子湖主要指标浓度 Global Moran's I 值及 显著性水平检验结果

Tab.1 Global Moran's I value of main water quality parameters in each season and the test result of significance level at Lake Liangzi

\begin{tabular}{ccccl}
\hline 季节 & $\mathrm{COD}_{\mathrm{Mn}}$ & $\mathrm{TP}$ & $\mathrm{TN}$ & $\mathrm{NH}_{3}-\mathrm{N}$ \\
\hline 春 & -0.045 & $0.189^{* *}$ & $0.521^{* *}$ & $0.165^{*}$ \\
夏 & $0.588^{* *}$ & $0.636^{* *}$ & $0.737^{* *}$ & $0.470^{* *}$ \\
秋 & $0.209^{* *}$ & $0.401^{* *}$ & 0.004 & $0.328^{* *}$ \\
冬 & $0.502^{* *}$ & $0.450^{* *}$ & 0.093 & $0.461^{* *}$ \\
\hline
\end{tabular}

*表示检验结果显著 $(P<0.05)$, **表示检验结果高度 显著 $(P<0.01)$. 
要分布在西梁子湖的大部分区域,以及东梁子湖和牛山湖的局部区域(图 5b).
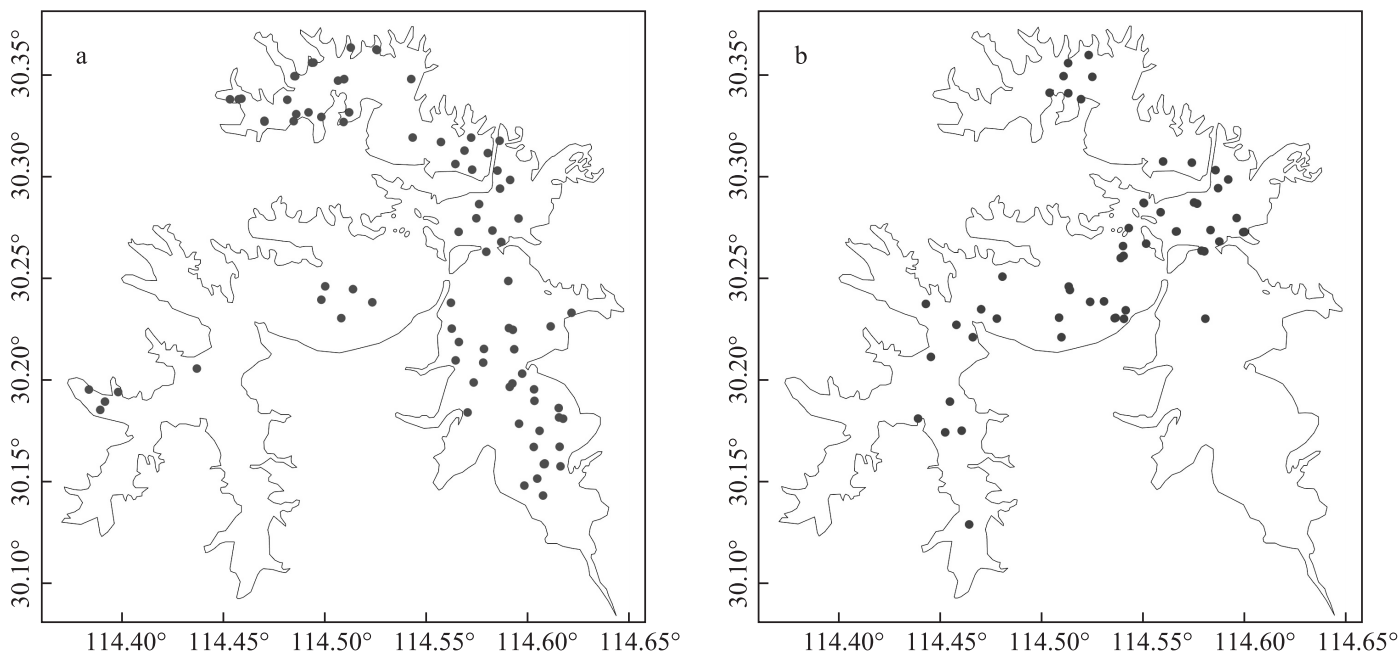

图 5 梁子湖水质高值聚集 (a) 和低值聚集 $(b)$ 空间分布

Fig.5 Spatial distribution of $\mathrm{HH}(\mathrm{a})$ and $\operatorname{LL}(\mathrm{b})$ cluster patterns of water quality at Lake Liangzi

\section{4 讨论}

本文依据大样本采样数据, 分春、夏、秋、冬季, 从点位、湖区、全局 3 个层次对梁子湖的水质状况、达标 情况和水质空间差异进行分析、比较和综合,结果发现: (1) 梁子湖整体受到污染主要表现在夏、秋季的 $\mathrm{COD}_{\mathrm{Mn}}$ 浓度较高, 冬季的 $\mathrm{TN}$ 浓度较高; (2) 春季水质超标主要表现在牛山湖和西梁子湖的 $\mathrm{TN}$ 污染, 夏季水 质超标主要表现在梁子湖整体的 $\mathrm{COD}_{\mathrm{Mn}}$ 污染以及牛山湖和西梁子湖的 $\mathrm{TN}$ 污染, 秋季水质超标主要表现在 梁子湖整体的 $\mathrm{COD}_{\mathrm{Mn}}$ 污染, 冬季水质超标主要表现在梁子湖整体的 TN 污染以及牛山湖的 $\mathrm{COD}_{\mathrm{Mn}}$ 和 $\mathrm{NH}_{3}-\mathrm{N}$ 污染; ( 3) 梁子湖水质空间分布不均主要表现在夏季的 TP 和 TN, 秋季的 $\mathrm{TP}$, 冬季的 $\mathrm{COD}_{\mathrm{Mn}}$ 浓度空间差异较 大. 结合水质空间分布模式, 可以看出, 梁子湖水质存在显著的季节差异和较大的空间差异: (1) 季节上, 夏、 秋、冬季污染相对较重, 春季污染相对较轻; 夏、秋季主要污染指标为 $\mathrm{COD}_{\mathrm{Mn}}$, 冬季为 $\mathrm{TN} ;(2)$ 空间上, 东梁子 湖和牛山湖污染相对较重, 西梁子湖污染相对较轻, 且多为面源污染; 东梁子湖主要污染指标为 $\mathrm{COD}_{\mathrm{Mn}} 、 \mathrm{TP}$ 和 $\mathrm{TN}$,牛山湖为 $\mathrm{COD}_{\mathrm{Mn}} 、 \mathrm{TN}$ 和 $\mathrm{NH}_{3}-\mathrm{N}$, 西梁子湖为 $\mathrm{COD}_{\mathrm{Mn}}$ 和 $\mathrm{TN}$.

梁子湖受到农业面源、水产养殖、城乡生活污水、集约化畜禽养殖、工业废水等多重污染压力 ${ }^{[25]}$. 农业 面源污染主要表现在农业生产活动中, $\mathrm{N} 、 \mathrm{P}$ 等营养物质、农药以及其他有机或无机物质, 通过地表径流和农 田渗漏进人湖泊 ${ }^{[35-36]}$, 导致 $\mathrm{COD}_{\mathrm{Mn}}$ 、 $\mathrm{TP}$ 和 $\mathrm{TN}$ 浓度较高; 夏季是农田生产活动最频繁的季节, 进人秋季之后, 这些活动逐渐减少, $\mathrm{COD}_{\mathrm{Mn}}$ 、 $\mathrm{TP}$ 和 $\mathrm{TN}$ 浓度逐渐下降; 但由于梁子湖属于浅水草型湖泊, 沉水植物丰富、生物 量高 ${ }^{[37]}$, 水生植物在 10 月底前后自然死亡, 参考厉恩华等 ${ }^{[38]}$ 对同类型湖泊一一洪湖的研究结果, 水生植物 调落物腐烂分解 90 天内有 $41 \%$ 的氮可释放到水体中, 从而导致冬季 TN 浓度较高. 梁子湖水产养殖主要包 括湖周边渔业养殖和湖内围网养殖两种形式 ${ }^{[25]}$, 夏季是水产摄食量最大、生长最快的季节, 投㙁量大, 导致 $\mathrm{COD}_{\mathrm{Mn}}$ 和 $\mathrm{TN}$ 浓度较高; 秋季水产成熟, 收获时对水体的扰动较大, 导致 $\mathrm{COD}_{\mathrm{Mn}}$ 浓度较高; 进人冬季后, $\mathrm{COD}_{\mathrm{Mn}}$ 浓度逐渐下降, 但由于湖内围网养殖的过量饵料、动植物残体及其排泄物等腐烂产生的 $\mathrm{NH}_{3}$ 直接进人 上层水体 ${ }^{[39]}$, 导致 $\mathrm{NH}_{3}-\mathrm{N}$ 浓度上升, 而 $\mathrm{NH}_{3}$ 在水体中发生硝化作用 ${ }^{[40]}$, 导致 $\mathrm{TN}$ 浓度上升; 至春季, $\mathrm{NH}_{3}-\mathrm{N}$ 基本完成转化或逸出水体, 浓度较低, 但 $\mathrm{TN}$ 浓度依然较高. 城乡生活污水、集约化畜禽养殖和工业废水等也 会排放一定量的污染物,但季节差异不明显.

结合上述污染源的季节性变化特点与梁子湖的水质时空格局推断, 东梁子湖主要受到农业面源和湖内 围网水产养殖的双重污染, 但夏季 $\mathrm{NH}_{3}-\mathrm{N}$ 浓度较高; 牛山湖主要受到湖内围网水产养殖的污染, 但冬季 
$\mathrm{COD}_{\mathrm{Mn}}$ 浓度较高; 西梁子湖主要受到湖内围网水产养殖的污染. 浓度较高的指标可能是由城乡生活污水、集 约化畜禽养殖和工业废水等其他污染源所致.

梁子湖作为湖北省第二大湖泊, 已有很多水环境方面的相关研究, 如前面提及的梁子湖水环境质量评 价 ${ }^{[22]}$, 梁子湖流域水环境功能区划及水质现状分析 ${ }^{[23]}$, 梁子湖水生生物多样性及水质评价研究 ${ }^{[24]}$ 等. 与之 前的研究相比, 本文布设的采样点更多、覆盖范围更大, 因此能够更好地反映梁子湖的水质空间分布特征. 不但如此, 本文在研究方法上也有所创新. 可以看出, 本文采用的点位、湖区和全局 3 个层次的时空格局分 析方法互相印证, 互为补充, 对全面、细致地了解梁子湖区的水质季节变化和空间差异极有帮助. 而且, 整个 分析过程被程序化,这将极大地方便梁子湖水环境的后续研究,也可为其他同类问题提供方法借鉴.

\section{5 结论}

1) 水质状况: 梁子湖整体 $\mathrm{COD}_{\mathrm{Mn}}$ 浓度在夏、秋季相对较高, 春、冬季相对较低; TP 浓度在春季相对较低; $\mathrm{TN}$ 浓度在冬季相对较高; $\mathrm{NH}_{3}-\mathrm{N}$ 浓度在春、秋季相对较低.

2) 达标情况: 东梁子湖夏、秋季的 $\mathrm{COD}_{\mathrm{Mn}}$ 以及冬季的 $\mathrm{TN}$ 超标较严重; 牛山湖春季的 $\mathrm{TN}$ 超标较严重,夏 季的 $\mathrm{COD}_{\mathrm{Mn}}$ 和 $\mathrm{TN}$ 、秋季的 $\mathrm{COD}_{\mathrm{Mn}}$ 以及冬季的 $\mathrm{COD}_{\mathrm{Mn}}$ 、 $\mathrm{TN}$ 和 $\mathrm{NH}_{3}-\mathrm{N}$ 超标非常严重; 西梁子湖春季的 $\mathrm{TN}$ 超标 较严重,夏季的 $\mathrm{COD}_{\mathrm{Mn}}$ 和 $\mathrm{TN}$ 、秋季的 $\mathrm{COD}_{\mathrm{Mn}}$ 以及冬季的 $\mathrm{TN}$ 超标非常严重.

3) 水质空间差异:梁子湖夏季 TP 和 TN 浓度空间差异较大,秋季 TP 浓度空间差异较大,冬季 $\mathrm{COD}_{\mathrm{Mn}}$ 浓 度空间差异较大.

4) 梁子湖水质存在显著的季节差异和较大的空间差异:季节上,夏、秋、冬季污染相对较重,春季污染相 对较轻;空间上,东梁子湖和牛山湖污染相对较重,西梁子湖污染相对较轻.

5) 东梁子湖主要受到农业面源和湖内围网水产养殖的双重污染; 牛山湖和西梁子湖主要受到湖内围网 水产养殖的污染.

\section{6 参考文献}

[ 1 ] Yang Guishan, Ma Ronghua, Zhang Lu et al. Lake status, major problems and protection strategy in China. J Lake Sci, 2010, 22(6) : 799-810(in Chinese with English abstract). DOI : 10.18307/2010.0601. [杨桂山, 马荣华, 张路等. 中国 湖泊现状及面临的重大问题与保护策略. 湖泊科学, 2010, 22(6) : 799-810.]

[ 2 ] Wang Sumin, Dou Hongshen eds. The lakes of China. Beijing: Science Press, 1998(in Chinese). [王苏民, 窦鸿身. 中 国湖泊志. 北京: 科学出版社, 1998.]

[ 3 ] Ministry of Environmental Protection of the People's Republic of China. 2014 Report on the State of the Environment of China(in Chinese). [中华人民共和国环境保护部. 2014 中国环境状况公报.]

[ 4 ] GB 3838-2002. Environmental quality standards for surface water. Beijing: China Environmental Science Press, 2002 (in Chinese). [GB 3838-2002. 地表水环境质量标准. 北京: 中国环境科学出版社, 2002.]

[ 5 ] State Administration of Environmental Protection ed. Analysis in water and wastewater. Beijing: China Environmental Science Press, 2002(in Chinese). [ 国家环境保护总局. 水和废水监测分析方法. 北京: 中国环境科学出版社, 2002.]

[ 6 ] Zeng H, Wu J. Heavy metal pollution of lakes along the mid-lower reaches of the Yangtze River in China: intensity, sources and spatial patterns. International Journal of Environmental Research and Public Health, 2013, 10: 793-807. DOI: 10.3390/ijerph10030793.

[ 7 ] Chang H. Spatial analysis of water quality trends in the Han River basin, South Korea. Water Research, 2008, 42: 3285 3304. DOI : 10.1016/j.watres.2008.04.006.

[ 8 ] Bu H, Tan X, Li S et al. Temporal and spatial variations of water quality in the Jinshui River of the South Qinling Mts, China. Ecotoxicology and Environmental Safety, 2010, 73: 907-913. DOI: 10.1016/j.ecoenv. 2009.11.007.

[ 9 ] Cheruvelil KS, Soranno PA, Bremigan MT et al. Grouping lakes for water quality assessment and monitoring: the roles of regionalization and spatial scale. Environmental Management, 2008, 41: 425-440. DOI: 10.1007/s00267-007-9045-7.

[10] Dekker AG, Peters SWM. The use of the Thematic Mapper for the analysis of eutrophic lakes: a case study in the Netherlands. International Journal of Remote Sensing, 1993, 14(5) : 799-821. DOI: 10.1080/0143116930 8904379.

[11] Ban Xuan, Du Yun, Wu Qiuzhen et al. The spatial distribution of water environment pollution state and the analysis of the 
source of pollution in the Sihu basin. Resources and Environment in the Yangtze Basin, 2011, 20(Z1): 112-116( in Chinese with English abstract). [班璇, 杜耘, 吴秋珍等. 四湖流域水环境污染现状空间分布和污染源分析. 长江流域 资源与环境, $2011, \mathbf{2 0}(\mathrm{Z1})$ : 112-116.]

[12] Wang Shuhang, Wang Wenwen, Jiang Xia et al. Spatial-temporal dynamic changes of nitrogen and phosphorus and difference analysis in water body of Lihu Lake. China Environmental Science, 2014, 34(5) : 1268-1276(in Chinese with English abstract). [王书航, 王雯雯, 姜霞等. 蟙湖水体氮、磷时空变化及差异性分析. 中国环境科学, 2014, 34(5): 1268-1276.]

[13] Zhang Yunlin, Yang Longyuan, Qin Boqiang et al. Spatial distribution of COD and the correlations with other parameters in the northern region of Lake Taihu. Environmental Science, 2008, 29(6): 1457-1462 (in Chinese with English abstract). DOI: 10.3321/j.issn:0250-3301.2008.06.001. [张运林, 杨龙元, 秦伯强等. 太湖北部湖区 COD 浓度空间 分布及与其它要素的相关性研究. 环境科学, 2008, 29(6) : 1457-1462.]

[14] Jones RC, Kelso DP, Schaeffer E. Spatial and seasonal patterns in water quality in an embayment-mainstem reach of the tidal freshwater Potomac River, USA: a multiyear study. Environmental Monitoring and Assessment, 2008, 147: 351-375. DOI : $10.1007 / \mathrm{s} 10661-007-0126-0$.

[15] Alberto WD, Del Pilar DM, Valeria AM et al. Pattern recognition techniques for the evaluation of spatial and temporal variations in water quality. A case study: Suquía River Basin (Córdoba-Argentina). Water Research, 2001, 35(12) : 28812894. DOI: 10.1016/s0043-1354(00)00592-3.

[16] Vega M, Pardo R, Barrado E et al. Assessment of seasonal and polluting effects on the quality of river water by exploratory data analysis. Water Research, 1998, 32(12) : 3581-3592. DOI : 10.1016/S0043-1354(98) 00138-9.

[17] Shrestha S, Kazama F. Assessment of surface water quality using multivariate statistical techniques: a case study of the Fuji river basin, Japan. Environmental Modeling \& Software, 2007, 22: 464-475. DOI: 10.1016/j. envsoft.2006.02.001.

[18] Zhang Xuan, Wang Qishan, Yu Miao et al. Application of multivariate statistical techniques to water quality monitoring. China Water \& Wastewater, 2010, 26(11) : 120-126(in Chinese with English abstract). [张旋, 王启山, 于沝等. 多元 统计分析技术在水质监测中的应用. 中国给水排水, 2010, 26(11): 120-126.]

[19] Fu Baorong, Su Jie, Wu Dan et al. Evaluation of temporal and spatial differences of water environment in Liaohe Basin. Water Resources Protection, 2011, 27(6) : 5-8(in Chinese with English abstract). DOI : 10.3969/j. issn. 1004-6933.2011. 06.002. [付保荣，苏杰，吴丹等. 辽河流域水环境时空差异性评价. 水资源保护，2011，27(6) : 5-8.]

[20] Lü Heng, Jiang Nan, Li Xinguo. The study on water quality of inland lake monitoring by remote sensing. Advances in Earth Science, 2005, 20(2) : 185-192 (in Chinese with English abstract). DOI: 10.3321/j.issn: 1001-8166.2005.02.008. [吕 恒, 江南, 李新国. 内陆湖泊的水质遥感监测研究. 地球科学进展, 2005, 20(2): 185-192.]

[21] Tufford DL, McKellar HN. Spatial and temporal hydrodynamic and water quality modeling analysis of a large reservoir on the South Carolina (USA) coastal plain. Ecological Modelling, 1999, 114: 137-173. DOI: 10. 1016/S0304-3800(98) $00122-7$.

[22] Zhang Wenman, Wang Zibin, Gan Hua et al. Assessment of water environment quality in Lake Liangzi. Environmental Science \& Technology, 2005, 28(Z) : 102-103 (in Chinese with English abstract). DOI: 10.3969/j.issn. 1003-6504.2005. z1.046. [张文漫，汪自斌，干华等. 梁子湖水环境质量评价. 环境科学与技术，2005，28(Z): 102-103.]

[23] Gu Ziqiang, Gao Fei, Wang Zhouyuan. Water environmental function zoning and water quality status analysis in Lake Liangzi Basin. Chinese Journal of Environmental Management, 2014, 6( 5) : 32-36( in Chinese with English abstract). DOI: 1674-6252(2014)05-0032-06. [顾自强, 高飞, 汪周园. 梁子湖流域水环境功能区划及水质现状分析. 中国环境管 理, 2014, 6(5): 32-36.]

[24] Wu Weiju, Wang Lingling, Zhang Bin et al. Investigation on biodiversity of aquatic organisms and water quality in Lake Liangzi. Environmental Science \& Technology, 2014, 37 (10): 199-204 (in Chinese with English abstract). DOI: 10. 3969/j.issn.1003-6504.2014.10.039. [ 吴卫菊, 王玲玲, 张斌等. 梁子湖水生生物多样性及水质评价研究. 环境科学 与技术, 2014, 37(10): 199-204.]

[25] Li Zhaohua, Sun Dazhong eds. Study on the ecological environment protection of Liangzihu Lake. Beijing: Science Press, 2009 (in Chinese). [ 李兆华, 孙大钟. 梁子湖生态环境保护研究. 北京: 科学出版社, 2009. ]

[26] Hubei Province Environmental Protection Bureaued. The function zone classification of surface water in Hubei Province, 2000 (in Chinese). [ 湖北省环境保护局. 湖北省地表水环境功能区类别, 2000.] 
[27] HJ 494-2009. Water quality-Guidance on sampling techniques. Beijing: Environmental Science Press, 2009 (in Chinese). [ HJ 494-2009. 水质 采样技术指导. 北京: 中国环境科学出版社, 2009. ]

[28] GB 11892-1989. Water quality-Determination of permanganate index. Beijing: Environmental Science Press, 1989(in Chinese ). [ GB 11892-1989. 水质高镇酸盐指数的测定.北京: 中国环境科学出版社, 1989.]

[29] GB 11893-1989. Water quality-Determination of total phosphorus-Ammonium molybdate spectrophotometric method. Beijing: Environmental Science Press, 1989 (in Chinese). [ GB 11893-1989. 水质总磷的测定 钼酸铵分光光度法. 北 京: 中国环境科学出版社, 1989.]

[30] GB 11894-1989. Water quality-Determination of total nitrogen-Alkaline potassium persulfate digestion-UV spectrophotometric method. Beijing: Environmental Science Press, 1989(in Chinese). [ GB 11894-1989. 水质总氮的测定 碱性过 硫酸钾消解紫外分光光度法. 北京: 中国环境科学出版社, 1989.]

[31] HJ 535-2009. Water quality-Determination of ammonia nitrogen-Nessler's reagent spectrophotometry. Beijing: Environmental Science Press, 2009 (in Chinese). [ HJ 535-2009. 水质 氨氮的测定 纳式试剂分光光度法. 北京: 中国环境 科学出版社, 2009.]

[32] Moran PAP. Notes on continuous stochastic phenomena. Biometrika, 1950, 37(1) : 17-23. DOI: 10.1093/bio met/ 37.12.17 .

[33] Anselin L. Local indicators of spatial association-LISA. Geographical Analysis, 1995, 27(2) : 93-115. DOI: 10. 1111/j. 1538-4632.1995.tb00338.x.

[34] Tian Qing, Chen Meiyang, Tian Huiyun eds. ArcGIS Geographic Information System guidance. Beijing: Beijing Hope Electronic Press, 2014(in Chinese). [田庆, 陈美阳, 田慧云. ArcGIS 地理信息系统详解( 10.1 版). 北京: 北京希望 电子出版社, 2014.]

[35] Li Xiufen, Zhu Jinzhao, Gu Xiaojun et al. The progress on agricultural surface source pollution status and prevention and control. China Population, Resources and Environment, 2010, 20(4) : 81-84(in Chinese with English abstract). DOI: 10.3969/j.issn.1002-2104.2010.04.014. [李秀芬, 朱金兆, 顾晓君等. 农业面源污染现状与防治进展. 中国人口 · 资源与环境, $2010, \mathbf{2 0}(4): 81-84$. ]

[36] Xiong Hanfeng, Wan Xihua. Investigation of nitrogen and phosphorus loadings on Liangzi Lake from agricultural non-point source. Environmental Science \& Technology, 2008, 31(2) : 25-27 (in Chinese with English abstract). DOI: 10.3969/j. issn.1003-6504.2008.02.007. [ 熊汉锋, 万细华. 农业面源氮磷污染对湖泊水体富营养化的影响. 环境科学与技术, $2008, \mathbf{3 1}(2): 25-27$.

[37] Ge Jiwen, Cai Qinghua, Liu Jiankang et al. The present situation and evaluation of plant diversity of Lake Liangzihu wetland. China Environmental Science, 2003, 23(5) : 451-456 (in Chinese with English abstract). DOI: 10.3321/j. issn: 1000-6923.2003.05.002. [ 葛继稳, 蔡庆华, 刘建康等. 梁子湖湿地植物多样性现状与评价. 中国环境科学, 2003, $23(5): 451-456$.

[38] Li Enhua, Liu Guihua, Li Wei et al. Decomposition rate and nitrogen and phosphorus dynamics of three kinds of hydrophyte in Lake Honghu. China Environmental Science, 2006, 26(6) : 667-671 (in Chinese with English abstract). DOI: 10.3321/j.issn: 1000-6923.2006.06.007. [ 万恩华, 刘贵华, 李伟等. 洪湖三种水生植物的分解速率及氮、磷动态. 中 国环境科学, 2006, 26(6): 667-671.]

[39] Liu Hao, Dong Ying, Tian Lingling. The effects of lake aquiculture on the lake ecosystem in Hubei. Hubei Agricultural Sciences, 2011, 50(9) : 1789-1792 (in Chinese with English abstract). DOI: 10.3969/j.issn.0439-8114.2011.09.019. [刘] 浩, 董芗, 田玲玲. 湖北省湖泊水产养殖对湖区生态系统的影响. 湖北农业科学, 2011, 50(9) : 1789-1792.]

[40] Li Gu, Wu Zhenbin, Hou Yansong et al. Nitrogen biotransformation and its relative microorganism in aquaculture waters. Chinese Journal of Eco-Agriculture, 2006, 14(1) : 11-15(in Chinese with English abstract). [李谷, 吴振斌, 侯燕松等. 养殖水体氮的生物转化及其相关微生物研究进展. 中国生态农业学报, 2006, 14(1): 11-15.] 